\title{
BMJ Open How representative are colorectal, lung, breast and prostate cancer patients responding to the National Cancer Patient Experience Survey (CPES) of the cancer registry population in England? A population-based case control study
}

Saleh A Alessy (D) , ${ }^{1,2}$ Elizabeth A Davies, ${ }^{1}$ Janette Rawlinson, ${ }^{3}$ Matthew Baker, ${ }^{4}$ Margreet Lüchtenborg ${ }^{1,5}$

To cite: Alessy SA, Davies EA, Rawlinson J, et al. How representative are colorectal, lung, breast and prostate cancer patients responding to the National Cancer Patient Experience Survey (CPES) of the cancer registry population in England? A population-based case control study. BMJ Open 2019:9:e034344. doi:10.1136/ bmjopen-2019-034344

- Prepublication history for this paper is available online. To view these files, please visit the journal online (http://dx.doi. org/10.1136/bmjopen-2019034344).

Received 16 September 2019 Revised 15 November 2019 Accepted 20 November 2019

Check for updates

(c) Author(s) (or their employer(s)) 2019. Re-use permitted under CC BY-NC. No commercial re-use. See rights and permissions. Published by BMJ.

For numbered affiliations see end of article.

Correspondence to

Mr Saleh A Alessy;

saleh.alessy@kcl.ac.uk

\section{ABSTRACT}

Objective To assess the representativeness of National Cancer Patient Experience Survey (CPES) responders compared with the English cancer registry population in term of age, sex, socioeconomic deprivation, ethnicity, disease stage and median survival.

Design Population-based case-control study.

Setting England.

Population We identified 103186 colorectal, lung, breast and prostate cancer patients responding to at least one survey during 2010-2014 and randomly selected one nonresponder from the cancer registry matched on cancer type and yearly quarter of diagnosis.

Main outcome measure We compared age, sex, socioeconomic deprivation, ethnicity and disease stage between the two groups using logistic regression. We also compared survival (in years) using the Mann-Whitney test. Results Across all cancer types survey responders were younger, more likely to have a White ethnic background, to be resident in less deprived areas and diagnosed with earlier stage disease although they varied between cancers. Median survival for responders was also higher than for the cancer registry population (colorectal: 4.8 vs 3.2; lung: 2.0 vs 0.3 ; breast: 5.7 vs 5.4 ; and prostate: 5.7 vs 5.2 years; all $p$-values $<0.001$ ).

Conclusion CPES responders with the four most common cancers do not necessarily represent all patients with these cancers in terms of demographic characteristics and tumour stage at diagnosis. These limitations should be considered when interpreting findings. To capture the experiences of patients currently underrepresented in CPES, different approaches may need to be taken.

\section{INTRODUCTION}

Patient experience surveys now play a major role internationally in assessing patients' care experiences, monitoring services and improving care quality and outcomes. ${ }^{1-9}$ In England, there has been an increasing emphasis on improving patients' experiences

\section{Strengths and limitations of this study}

- This is the first study to compare National Cancer Patient Experience Survey responders directly to the wider cancer population diagnosed with the most common cancers in England.

- The large sample size allowed a detailed comparison of demographic characteristics and tumour stage at diagnosis.

- Data completeness for stage and ethnicity information in the cancer registry data were lower for patients diagnosed before 2012 .

of National Health Service (NHS) cancer care. ${ }^{1011}$ The National Cancer Patient Experience Survey (CPES) has invited a large sample of patients who received cancer care for all cancer types annually since 2010 to report their experiences. ${ }^{12}$ These data are fed back to local NHS Cancer Services, reported nationally and used for policy development and research. Studies published from different years of CPES indicate that experiences have been improving across many domains but that systematic differences in cancer patient experience by patient sociodemographic factors remain. ${ }^{13-17}$

Although population-based health experience surveys provide a valuable patient perspective on many aspects of health services, they are prone to selection biases ${ }^{18-20}$ that might result from missing the experiences of ethnic minorities, people living in the more deprived areas and the youngest and oldest age groups. In addition, there has been a concern that patients with the poorest prognosis are missed, because they are too ill or die before they can complete the survey. ${ }^{20} 21$ 


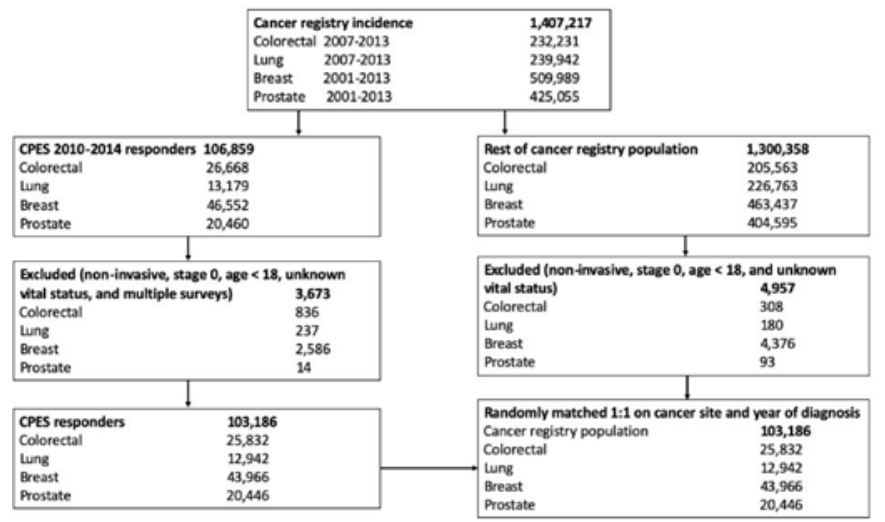

Figure 1 Study participants flow chart. All cancer incidences were first extracted. National Cancer Patient Experience Survey (CPES) responders were then separated from cancer registry population before randomly matching $1: 1$ on cancer diagnosis and quarter year of diagnosis.

Analysis of early cancer experience surveys in England in 2000 and 2004, for example, showed limited inclusion of lung cancer patients, ${ }^{10}$ and analysis of CPES data for 2010 raised a concern about the number of patients in the initial sampling frame for some cancer types who died before they could receive they survey. ${ }^{20} 21$

The National Cancer Registration and Analysis Service (NCRAS) collects data on all incident cancer diagnoses in England. ${ }^{22}$ Focusing on the four most common cancers in England (colorectal, lung, breast and prostate), we aimed to compare the survey responders' demographic and tumour stage at diagnosis and their median survival time to determine the extent to which they represent the cancer registry population and to inform future surveys.

\section{METHODS}

\section{CPES data linkage}

CPES is conducted by Quality Health on behalf of NHS England and contains around 70 questions covering many aspects of cancer care experience ranging from seeing the general practitioner, receiving in-patient care and treatment to outpatient follow-up. For the analysis presented here, we focused on the four iterations of the survey between 2010 and 2014. The survey sampling frame includes all adult patients with a primary diagnosis of cancer who have been discharged from an NHS hospital either as an inpatient or day patient during a 3-month period in each year. Patients are invited to complete the survey by post, with two reminders being sent to nonresponders. The response rate to the survey was stable (64\%-68\%) between 2010 and 2014. NCRAS has recently linked the CPES data set to the English population cancer registry through matching on patients unique identifier (NHS number) and the International Classification of Diseases (V.10) (ICD-10) 3-digit site code to enable researchers to explore the associations between cancer patients' experiences and their clinical outcomes. ${ }^{23}$

\section{Study population}

NCRAS collects data on all cancers diagnosed in England. This includes demographic information, date of diagnosis, treatment and vital status through the Office for National Statistics. ${ }^{22}$ The survey, however, includes only patients discharged in a recent 3-month period from hospital, regardless of their date of diagnosis. We found that for lung and colorectal cancer at least $95 \%$ of survey responders had their cancer diagnosed between 2007 and 2013 , while $95 \%$ of responders with breast and prostate cancers were diagnosed between 2001 and 2013 (figure 1). Thus, we extracted data for all patients diagnosed in those time periods with colorectal (C18-20), lung (C33-34), female breast (C50) and prostate (C61) cancers (ICD-10) from the cancer registration data (2016 closedown). ${ }^{22}$

Cancer in situ (stage 0), patients aged less than 18 years, and diagnoses based on death certificates only (not found among CPES responders) were excluded. We also excluded cases with unknown vital status. In addition, some patients have responded to the survey more than once for the same type of cancer. Therefore, out of 3673 cases excluded in CPES cohort, 3442 were due to being multiple records (figure 1).

We first removed all CPES responders from the cancer registry population. In order to make a fair comparison in terms of the follow-up time, diagnosis date, and data completeness, which changed over time, we randomly selected one patient who was not a CPES responder for each CPES responder, matched on cancer type and time of diagnosis (same yearly quarter) $(\mathrm{n}=103186)$ (figure 2$)$. To assess the robustness of our method, we repeated this method by taking another random sample from the cancer registry. We compared the two random samples and there were no differences with regard to sex, age, ethnicity, and socioeconomic deprivation, geographical area of residence, disease stage and survival.

For all patients, we included demographic data (sex, age, ethnicity, socioeconomic deprivation and geographical area of residence) and their survival and disease stage at diagnosis. Self-reported ethnicity data are obtained through linkage with the admitted patient care Hospital Episode Statistics (HES) data. ${ }^{24}$ We collapsed the 16-group classification into six categories: White, Asian, Black, Chinese, Mixed and Other. Patient's socioeconomic deprivation is assigned based on their postcode of residence at diagnosis, and based on the quintile distribution of lower layer super output areas (LSOAs), which covers around 1500 persons, using the income domain of the index of multiple deprivation (IMD) (with 1 being the least deprived and 5 being the most deprived).$^{25}$ Four versions of IMD were available (2004, 2007, 2010, 2015) and we applied the closest match of IMD to the year of diagnosis (IMD 2004 for diagnosis years 1999-2002; IMD 2007 for diagnosis years 2003-2006; IMD 2010 for diagnosis years 2007-2009; IMD 2015 for diagnosis years 2010-2013). Information on disease stage was extracted from the cancer registry system for all cancers, and for 


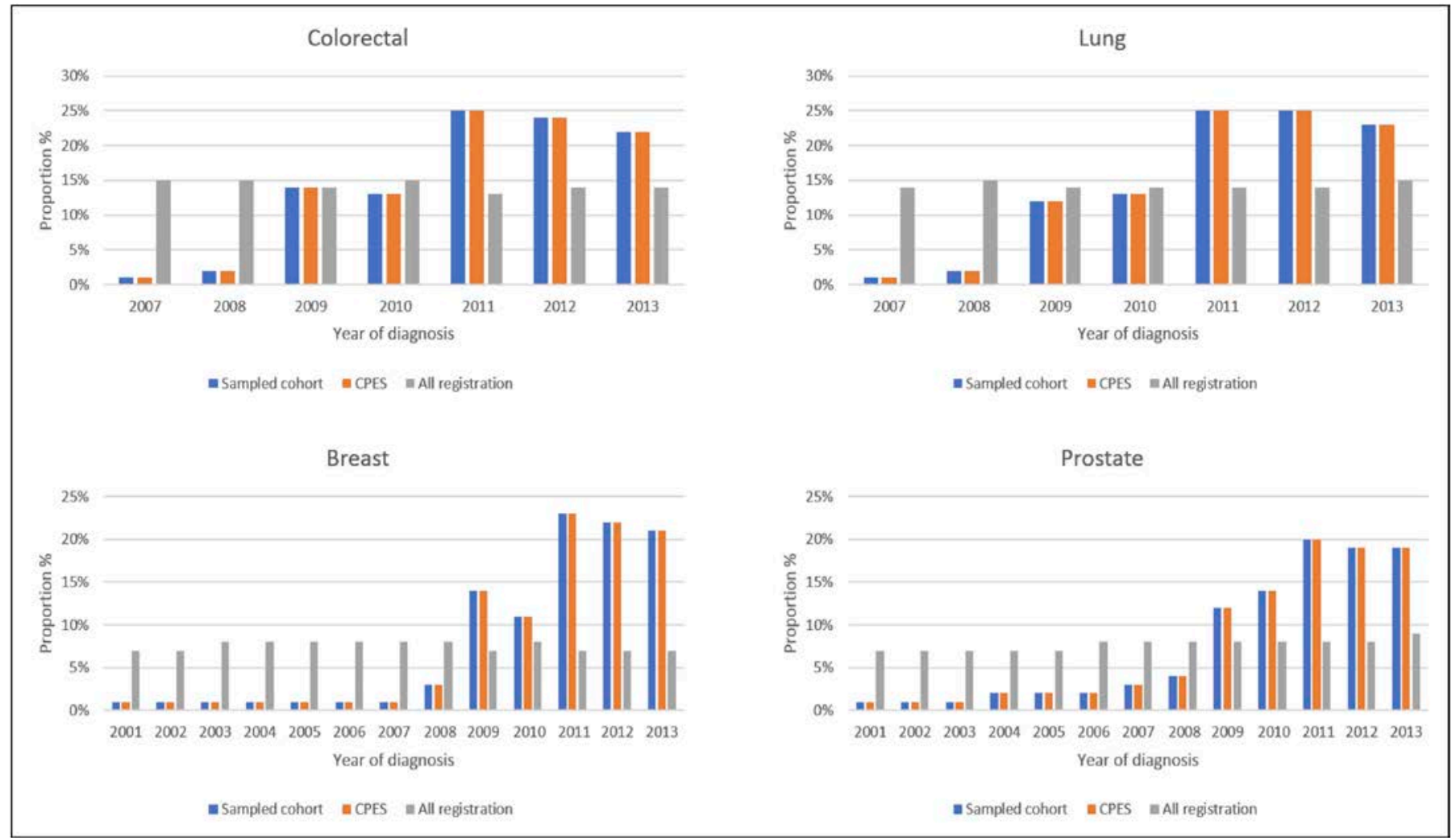

Figure 2 Distribution of year of diagnosis of the cancer registry compared with National Cancer Patient Experience Survey (CPES) and the sample we took for colorectal, lung, breast and prostate cancers. This graph shows the year of diagnosis for the entire cancer registry population compared with the CPES responders, and the study sample we took from the entire cancer registry population based on random matching with CPES responders on cancer type and quarter year of diagnosis.

lung cancer missing stage information was extracted from the National Lung Cancer Audit data set, which has a higher completeness of lung cancer stage data. ${ }^{26}$

\section{Data analysis}

A total number of 206372 patients were included in the analysis. We first compared the distribution of the patient characteristics (age, sex, socioeconomic deprivation, ethnicity, geographical areas) and disease stage among CPES responders and the cancer registry population using univariable and multivariable logistic regression. $\chi^{2}$ tests were performed to estimate the p-values for trend and heterogeneity excluding missing value categories, where p-values for trend were estimated by fitting the categorical variables linearly. We calculated survival time from the date of diagnosis until date of death. Patients who were still alive were censored on their last updated live status date in the cancer registration (between 5 and 10 January 2018). Where the date of death and date of diagnosis had the same date, we added 0.1 day to cancer registry population survival time (breast: $(n=2108)$, prostate: $(n=3140)$, lung: $(n=5436)$ and colorectal: $(n=2617))$. Finally, we compared median patient survival (in years) between the two groups using the Mann-Whitney test. All analyses were performed using Stata Software V.15 (StataCorp).

\section{RESULTS}

Tables 1-4 show the odds of being in the CPES group based on patient and tumour stage at diagnosis. Males were more likely to have responded to CPES than females among colorectal cancer patients but not among lung cancer patients (colorectal: adjusted OR 1.06, 95\% CI: 1.02 to 1.10; lung: adjusted OR $0.96,95 \%$ CI: 0.91 to $1.01)$. CPES responders were significantly younger than their registry counterparts across all cancers (median age: colorectal 68 vs 74 years, $\mathrm{p}<0.001$; lung 68 vs 73 years, $\mathrm{p}<0.001$; breast 58 vs 64 years, $\mathrm{p}<0.001$; prostate 67 vs 71 years, $\mathrm{p}<0.001)$. Patients with a non-White ethnic background were less likely to be in the CPES cohort across all cancers, although this was most statistically significant among people with an Asian background (colorectal: adjusted OR $0.67,95 \%$ CI: 0.57 to 0.80 ; lung: adjusted OR 0.73 , $95 \%$ CI: 0.57 to 0.94 ; breast: adjusted OR 0.67 , 95\% CI: 0.61 to 0.74 ; prostate: adjusted OR $0.79,95 \%$ CI: 0.65 to 0.96$)$. In addition, breast and prostate cancer patients from black ethnic background were less likely to be in the CPES cohort (breast: adjusted OR 0.81, 95\% CI: 0.72 to 0.92 ; prostate: adjusted OR $0.82,95 \%$ CI: 0.71 to 0.95 ), while patients from a Chinese ethnic background were less likely to be in the CPES cohort among breast cancer patients only (adjusted OR $0.67,95 \%$ CI: 0.50 to $0.88)$. 
Table 1 Odds of colorectal cancer patients diagnosed between 2007 and 2013 having responded to CPES according to case mix

\begin{tabular}{|c|c|c|c|c|c|c|c|c|}
\hline \multirow[b]{2}{*}{ Variable } & \multicolumn{2}{|c|}{$\begin{array}{l}\text { CPES } \\
(n=25832)\end{array}$} & \multicolumn{2}{|c|}{$\begin{array}{l}\text { Cancer registry } \\
\text { (non-CPES) } \\
(\mathrm{n}=25832)\end{array}$} & \multicolumn{2}{|c|}{ Univariable } & \multicolumn{2}{|c|}{ Mutually adjusted ${ }^{\star}$} \\
\hline & $\mathbf{N}$ & $\%$ & $\mathbf{N}$ & $\%$ & OR & $95 \% \mathrm{CI}$ & OR & $95 \% \mathrm{Cl}$ \\
\hline \multicolumn{9}{|l|}{ Sex } \\
\hline Female & 10636 & 41.2 & 11394 & 44.1 & reference & & refere & \\
\hline Male & 15196 & 58.8 & 14438 & 55.9 & 1.13 & 1.09 to 1.17 & 1.06 & 1.02 to 1.10 \\
\hline Heterogeneity test & & & & & \multicolumn{2}{|c|}{$\chi 2(1)=45.4 ; p<0.001$} & \multicolumn{2}{|c|}{$\chi^{2}(1)=9.2 ; p=0.002$} \\
\hline \multicolumn{9}{|l|}{ Age group } \\
\hline$<30$ & 75 & 0.3 & 135 & 0.5 & 0.86 & 0.65 to 1.14 & 0.96 & 0.72 to 1.28 \\
\hline $30-44$ & 721 & 2.8 & 688 & 2.7 & 1.63 & 1.46 to 1.81 & 1.71 & 1.53 to 1.91 \\
\hline $45-59$ & 4431 & 17.2 & 3133 & 12.1 & 2.19 & 2.08 to 2.32 & 2.24 & 2.12 to 2.37 \\
\hline $60-74$ & 13370 & 51.8 & 9801 & 37.9 & 2.12 & 2.03 to 2.20 & 2.13 & 2.04 to 2.21 \\
\hline $75-89$ & 7013 & 27.1 & 10880 & 42.1 & \multicolumn{2}{|l|}{ reference } & \multicolumn{2}{|c|}{ reference } \\
\hline $90+$ & 222 & 0.9 & 1195 & 4.6 & 0.29 & 0.25 to 0.33 & 0.31 & 0.27 to 0.36 \\
\hline Trend test & & & & & \multicolumn{2}{|c|}{$\chi 2(1)=1291.4 ; p<0.001$} & \multicolumn{2}{|c|}{$\chi^{2(1)=1281.3 ; p<0.001}$} \\
\hline \multicolumn{9}{|l|}{ Ethnicity } \\
\hline White & 22563 & 87.3 & 20836 & 80.7 & \multicolumn{2}{|l|}{ reference } & \multicolumn{2}{|c|}{ reference } \\
\hline Mixed & 43 & 0.2 & 46 & 0.2 & 0.86 & 0.57 to 1.31 & 0.87 & 0.56 to 1.33 \\
\hline Asian & 260 & 1.0 & 330 & 1.3 & 0.73 & 0.62 to 0.86 & 0.67 & 0.57 to 0.80 \\
\hline Black & 199 & 0.8 & 224 & 0.9 & 0.82 & 0.68 to 0.99 & 0.84 & 0.69 to 1.03 \\
\hline Chinese & 35 & 0.1 & 30 & 0.1 & 1.08 & 0.66 to 1.76 & 0.98 & 0.60 to 1.62 \\
\hline Other & 4 & 0.0 & 7 & 0.0 & 0.53 & 0.15 to 1.80 & 0.53 & 0.15 to 1.87 \\
\hline Unknown & 2728 & 10.6 & 4359 & 17.0 & 0.58 & 0.55 to 0.61 & 0.65 & 0.61 to 0.69 \\
\hline Heterogeneity test & & & & & \multicolumn{2}{|c|}{$\chi^{2}(5)=20.0 ; p=0.001$} & \multicolumn{2}{|c|}{$\chi 2(5)=22.8 ; p<0.001$} \\
\hline \multicolumn{9}{|l|}{ Area of residence } \\
\hline South East & 4116 & 15.9 & 4367 & 16.9 & \multicolumn{2}{|l|}{ reference } & \multicolumn{2}{|c|}{ reference } \\
\hline East Midlands & 2573 & 10.0 & 2215 & 8.6 & 1.23 & 1.15 to 1.32 & 1.07 & 0.99 to 1.15 \\
\hline East of England & 3075 & 11.9 & 3053 & 11.8 & 1.07 & 1.00 to 1.14 & 0.91 & 0.85 to 0.98 \\
\hline London & 2373 & 9.2 & 2591 & 10.0 & 0.97 & 0.91 to 1.04 & 1.08 & 1.00 to 1.16 \\
\hline North East & 1578 & 6.1 & 1457 & 5.6 & 1.15 & 1.06 to 1.25 & 1.14 & 1.04 to 1.24 \\
\hline North West & 3222 & 12.5 & 3659 & 14.2 & 0.93 & 0.88 to 1.00 & 0.92 & 0.86 to 0.99 \\
\hline South West & 3268 & 12.7 & 3117 & 12.1 & 1.11 & 1.04 to 1.19 & 1.02 & 0.95 to 1.09 \\
\hline West Midlands & 3060 & 11.8 & 2823 & 10.9 & 1.15 & 1.08 to 1.23 & 1.04 & 0.96 to 1.11 \\
\hline $\begin{array}{l}\text { Yorkshire and The } \\
\text { Humber }\end{array}$ & 2567 & 9.9 & 2550 & 9.9 & 1.07 & 1.00 to 1.14 & 0.99 & 0.92 to 1.07 \\
\hline Heterogeneity test & & & & & \multicolumn{2}{|c|}{$\chi 2(8)=89.5 ; p<0.001$} & \multicolumn{2}{|c|}{$\chi 2(8)=46.3 ; p<0.001$} \\
\hline Deprivation & & & & & & & & \\
\hline 1-(most affluent) & 5988 & 23.2 & 5404 & 20.9 & reference & & refere & \\
\hline 2 & 6370 & 24.7 & 5659 & 21.9 & 1.02 & 0.97 to 1.07 & 1.01 & 0.96 to 1.07 \\
\hline 3 & 5500 & 21.3 & 5430 & 21.0 & 0.91 & 0.87 to 0.96 & 0.92 & 0.87 to 0.97 \\
\hline 4 & 4551 & 17.6 & 4938 & 19.1 & 0.83 & 0.79 to 0.88 & 0.84 & 0.79 to 0.89 \\
\hline 5-(most deprived) & 3423 & 13.3 & 4401 & 17.0 & 0.7 & 0.66 to 0.74 & 0.69 & 0.65 to 0.73 \\
\hline Trend test & & & & & $\chi 2(1)=18$ & $p<0.001$ & $\chi^{2}(1)$ & $p<0.001$ \\
\hline Stage & & & & & & & & \\
\hline I & 2155 & 8.3 & 2473 & 9.6 & reference & & refere & \\
\hline
\end{tabular}




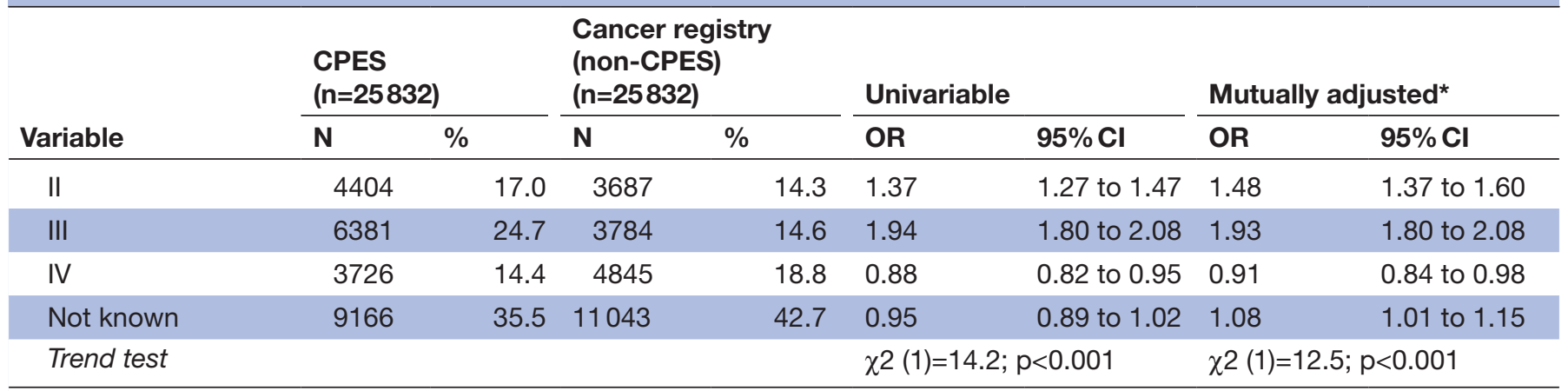

*Multivariable model including all factors; unknown stage and ethnicity categories were not included in tests for heterogeneity and trend.

CPES, National Cancer Patient Experience Survey.

In addition, living in more deprived areas was associated with the reduced odds of being in the CPES group across all cancers: colorectal (adjusted OR 0.69, 95\% CI: 0.65 to 0.73 for most vs least deprived), lung (adjusted OR $0.65,95 \%$ CI: 0.60 to 0.71 for most vs least deprived), breast (adjusted OR 0.84, 95\% CI: 0.80 to 0.88 for most vs least deprived) and prostate (adjusted OR $0.83,95 \% \mathrm{CI}$ : 0.78 to 0.90 for most vs least deprived). Generally, CPES responders were more likely to be resident in areas other than the South East or North West. However, among prostate cancer patients, responders to the CPES were most likely to be resident in the North West (adjusted OR 2.04, 95\% CI: 1.89 to 2.19 for North West vs South East).

In general, when comparing cancer stage at diagnosis between the two cohorts, CPES responders were more likely to be diagnosed with stage II and III disease and less likely to be diagnosed with stage IV disease. The proportions of missing stage information were lower among CPES responders across all cancers. CPES responders with colorectal and breast cancers were more likely to be diagnosed with stage II (colorectal: adjusted OR 1.48, 95\% CI: 1.37 to 1.60 ; breast: adjusted OR $1.54,95 \%$ CI: 1.49 to 1.60 ), and III (colorectal: adjusted OR 1.93, 95\% CI: 1.80 to 2.08; breast: adjusted OR $1.90,95 \%$ CI: 1.79 to 2.02) while CPES responders with lung cancer patients were more likely to be diagnosed with stage II (adjusted OR $1.40,95 \%$ CI: 1.25 to 1.60$)$. Survey responders had a significantly higher median survival compared with the cancer registry population across all cancers, with the largest difference in lung cancer and colorectal cancer (colorectal: 4.8 vs 3.2 years, $\mathrm{p}<0.001$; breast: 5.7 vs 5.4 years, $\mathrm{p}<0.001$; and prostate: 5.7 vs 5.2 years, $\mathrm{p}<0.001$; lung: 2.0 vs 0.3 years, $\mathrm{p}<0.001$ ).

\section{DISCUSSION}

\section{Summary of main findings}

This study examined how representative CPES responders for the four main cancers are compared with the cancer registry population with respect to individual characteristics and tumour stage at diagnosis. Overall, survey responders were younger, more likely to have a White ethnic background, to be living in less deprived areas and diagnosed at stages II and III across all cancer types. There was a small difference by sex among patients with colorectal cancer with males being more likely to be in the CPES responder group than females, but not for those with lung cancer. Median survival was generally higher in CPES responders, although the magnitude varied across different cancers and was most pronounced in lung and colorectal cancer patients.

\section{Comparison with other findings}

Our findings concerning the limited representativeness of the survey responders compared with the cancer registry population are consistent with two previous studies. ${ }^{10} 20$ Abel and colleagues examined those selected into the initial CPES sampling frame and found non-responders were more likely to be older, from more deprived areas, or diagnosed with poor prognosis cancers. These patients were more likely to have died in the 2-3 month period between the initial sampling and the mail out of the survey and so never received the survey. ${ }^{20}$ The variation in median survival between the survey responders and the cancer registry population in our study, especially for lung cancer, is very likely related to this issue but may also represent patients who received the survey but were too ill to complete and return it. Abel $e t a l^{20}$ findings are important when comparing CPES responders versus non-responders. However, their study focused on internal representativeness only, whereas we sought to address the question of how representative the CPES responders are of all patients diagnosed with one of the four most common cancers, and not only those who have had an inpatient experience. Although our findings are similar and align with theirs, our study is important when comparing the responders to wider cancer population with these cancer types. This is particularly important when using CPES findings to inform cancer care policy for all English patients.

It is of interest that CPES responders were more likely to be diagnosed with stage II or III disease compared with 
Table 2 Odds of lung cancer patients diagnosed between 2007 and 2013 having responded to CPES according to case mix

\begin{tabular}{|c|c|c|c|c|c|c|c|c|}
\hline \multirow[b]{2}{*}{ Variable } & \multicolumn{2}{|c|}{$\begin{array}{l}\text { CPES } \\
(n=12942) \\
\end{array}$} & \multicolumn{2}{|c|}{$\begin{array}{l}\text { Cancer registry (non- } \\
\text { CPES) } \\
(n=12942)\end{array}$} & \multicolumn{2}{|l|}{ Univariable } & \multicolumn{2}{|c|}{ Mutually adjusted* } \\
\hline & $\mathbf{N}$ & $\%$ & $\mathbf{N}$ & $\%$ & OR & $95 \% \mathrm{Cl}$ & OR & $95 \% \mathrm{Cl}$ \\
\hline \multicolumn{9}{|l|}{ Sex } \\
\hline Female & 5968 & 46.1 & 5793 & 44.8 & reference & & refere & \\
\hline Male & 6974 & 53.9 & 7149 & 55.2 & 0.95 & 0.90 to 0.99 & 0.96 & 0.91 to 1.01 \\
\hline \multicolumn{3}{|c|}{ Heterogeneity test } & & & \multicolumn{2}{|c|}{$\chi 2(1)=4.7 ; p=0.02$} & \multicolumn{2}{|c|}{$\chi^{2}(1)=2.6 ; p=0.10$} \\
\hline \multicolumn{9}{|l|}{ Age group } \\
\hline$<30$ & 13 & 0.1 & 16 & 0.1 & 0.58 & 0.28 to 1.21 & 0.73 & 0.34 to 1.56 \\
\hline $30-44$ & 148 & 1.1 & 119 & 0.9 & 0.89 & 0.70 to 1.14 & 1.05 & 0.81 to 1.35 \\
\hline $45-59$ & 2144 & 16.6 & 1406 & 10.9 & 1.09 & 1.01 to 1.18 & 1.19 & 1.10 to 1.28 \\
\hline $60-74$ & 7681 & 59.3 & 5513 & 42.6 & \multicolumn{2}{|l|}{ reference } & \multicolumn{2}{|c|}{ reference } \\
\hline $75-89$ & 2922 & 22.6 & 5397 & 41.7 & 0.39 & 0.37 to 0.41 & 0.38 & 0.36 to 0.41 \\
\hline $90+$ & 34 & 0.3 & 491 & 3.8 & 0.05 & 0.04 to 0.07 & 0.05 & 0.04 to 0.07 \\
\hline Trend test & & & & & $\chi 2(1)=1165$ & $7 ; p<0.001$ & $\chi 2(1)$ & $2 ; p<0.001$ \\
\hline \multicolumn{9}{|l|}{ Ethnicity } \\
\hline White & 11566 & 89.4 & 10287 & 79.5 & \multicolumn{2}{|l|}{ reference } & \multicolumn{2}{|c|}{ reference } \\
\hline Mixed & 23 & 0.2 & 19 & 0.1 & 1.08 & 0.59 to 1.98 & 0.75 & 0.40 to 1.39 \\
\hline Asian & 128 & 1.0 & 151 & 1.2 & 0.75 & 0.59 to 0.96 & 0.73 & 0.57 to 0.94 \\
\hline Black & 80 & 0.6 & 82 & 0.6 & 0.87 & 0.64 to 1.18 & 0.82 & 0.59 to 1.14 \\
\hline Chinese & 19 & 0.1 & 14 & 0.1 & 1.21 & 0.60 to 2.41 & 1.00 & 0.48 to 2.09 \\
\hline Other & 4 & 0.1 & 5 & 0.1 & 0.71 & 0.19 to 2.65 & 0.57 & 0.15 to 2.18 \\
\hline Unknown & 1122 & 8.7 & 2384 & 18.4 & 0.42 & 0.39 to 0.45 & 0.49 & 0.45 to 0.54 \\
\hline \multicolumn{3}{|c|}{ Heterogeneity test } & & & \multicolumn{2}{|c|}{$\chi^{2}(5)=6.8 ; p=0.23$} & \multicolumn{2}{|c|}{$\chi^{2}(5)=7.4 ; p=0.1$} \\
\hline \multicolumn{9}{|l|}{$\begin{array}{l}\text { Area of } \\
\text { residence }\end{array}$} \\
\hline South East & 1631 & 12.6 & 1903 & 14.7 & \multicolumn{2}{|l|}{ reference } & \multicolumn{2}{|c|}{ reference } \\
\hline $\begin{array}{l}\text { East } \\
\text { Midlands }\end{array}$ & 1266 & 9.8 & 1070 & 8.3 & 1.38 & 1.24 to 1.53 & 1.35 & 1.21 to 1.51 \\
\hline $\begin{array}{l}\text { East of } \\
\text { England }\end{array}$ & 1475 & 11.4 & 1368 & 10.6 & 1.26 & 1.14 to 1.39 & 1.17 & 1.05 to 1.30 \\
\hline London & 1320 & 10.2 & 1359 & 10.5 & 1.13 & 1.02 to 1.25 & 1.36 & 1.21 to 1.52 \\
\hline North East & 1034 & 8.0 & 944 & 7.3 & 1.28 & 1.14 to 1.43 & 1.27 & 1.13 to 1.44 \\
\hline North West & 1808 & 14.0 & 2229 & 17.2 & 0.95 & 0.86 to 1.04 & 0.94 & 0.85 to 1.04 \\
\hline South West & 1349 & 10.4 & 1229 & 9.5 & 1.28 & 1.16 to 1.42 & 1.21 & 1.09 to 1.35 \\
\hline $\begin{array}{l}\text { West } \\
\text { Midlands }\end{array}$ & 1354 & 10.5 & 1302 & 10.1 & 1.21 & 1.10 to 1.34 & 1.18 & 1.06 to 1.32 \\
\hline $\begin{array}{l}\text { Yorkshire and } \\
\text { The Humber }\end{array}$ & 1705 & 13.2 & 1538 & 11.9 & 1.29 & 1.18 to 1.42 & 1.25 & 1.12 to 1.39 \\
\hline Heterogeneity & test & & & & $\chi^{2}(8)=104$. & $p<0.001$ & $\chi^{2}(8)$ & $0<0.001$ \\
\hline \multicolumn{9}{|l|}{ Deprivation } \\
\hline $\begin{array}{l}1 \text { (most } \\
\text { affluent) }\end{array}$ & 2047 & 15.8 & 1726 & 13.3 & reference & & refere & \\
\hline 2 & 2603 & 20.1 & 2251 & 17.4 & 1.04 & 0.96 to 1.13 & 1.00 & 0.91 to 1.09 \\
\hline 3 & 2662 & 20.6 & 2595 & 20.1 & 0.92 & 0.84 to 1.00 & 0.85 & 0.78 to 0.93 \\
\hline 4 & 2733 & 21.1 & 2880 & 22.3 & 0.83 & 0.77 to 0.90 & 0.75 & 0.68 to 0.82 \\
\hline
\end{tabular}


Table 2 Continued

\begin{tabular}{|c|c|c|c|c|c|c|c|c|}
\hline \multirow[b]{2}{*}{ Variable } & \multicolumn{2}{|c|}{$\begin{array}{l}\text { CPES } \\
(n=12942)\end{array}$} & \multicolumn{2}{|c|}{$\begin{array}{l}\text { Cancer registry (non- } \\
\text { CPES) } \\
(n=12942)\end{array}$} & \multicolumn{2}{|c|}{ Univariable } & \multicolumn{2}{|c|}{ Mutually adjusted* } \\
\hline & $\mathbf{N}$ & $\%$ & $\mathbf{N}$ & $\%$ & OR & $95 \% \mathrm{Cl}$ & OR & $95 \% \mathrm{Cl}$ \\
\hline $\begin{array}{l}5 \text { (most } \\
\text { deprived) }\end{array}$ & 2897 & 22.4 & 3490 & 27.0 & 0.77 & 0.71 to 0.84 & 0.65 & 0.60 to 0.71 \\
\hline Trend test & & & & & $\chi^{2}(1)$ & $p<0.001$ & $\chi 2(1)$ & $p<0.001$ \\
\hline \multicolumn{9}{|l|}{ Stage } \\
\hline I & 2170 & 16.8 & 1422 & 11.0 & \multicolumn{2}{|c|}{ reference } & \multicolumn{2}{|c|}{ reference } \\
\hline II & 1672 & 12.9 & 765 & 5.9 & 1.43 & 1.28 to 1.60 & 1.40 & 1.25 to 1.56 \\
\hline III & 3759 & 29.0 & 2333 & 18.0 & 1.06 & 0.97 to 1.15 & 1.00 & 0.91 to 1.09 \\
\hline IV & 4210 & 32.5 & 6170 & 47.7 & 0.45 & 0.41 to 0.48 & 0.42 & 0.38 to 0.45 \\
\hline Not known & 1131 & 8.7 & 2252 & 17.4 & 0.33 & 0.30 to 0.36 & 0.36 & 0.33 to 0.40 \\
\hline Trend test & & & & & \multicolumn{2}{|c|}{$\chi 2(1)=696.9 ; p<0.001$} & \multicolumn{2}{|c|}{$\chi^{2}(1)=713.7 ; p<0.001$} \\
\hline
\end{tabular}

*Multivariable model including all factors; unknown stage and ethnicity categories were not included in tests for heterogeneity and trend. CPES, National Cancer Patient Experience Survey.

stage I. This may reflect a higher intensity of treatment through which they were more likely to be included in the sampling frame. Moreover, the low inclusion of patients with lung cancer patients as a proportion of the incidence is consistent with another study which found that the initial 2000 and 2004 patient experience surveys did not represent patients registered with lung cancer in South East England (the response rate for lung patients was between $6 \%$ and $28 \%$ in 2000 and 2004, respectively). ${ }^{10}$

\section{Strengths and limitations of this study}

To our knowledge, this study is the first to compare CPES responders directly to the cancer registry population using the CPES-NCRAS data linkage. One strength of our study is the large sample size, which allowed for detailed comparison of demographic and tumour stage at diagnosis between CPES responders and cancer registration patients for the four different cancer types. While most of CPES responders for every survey year were recently diagnosed patients admitted and discharged from cancer care, CPES has a backward tail of patients diagnosed in previous years, representing long-term survivors. The cancer registry population on the other hand is the annual cumulative incidence of all cancers diagnosed. We randomly selected one patient who was not a CPES responder for each CPES responder matched on cancer site and period of diagnosis (same yearly quarter) to eliminate survival time bias, and to get similar level of stage and ethnicity data completeness for both groups.

We recognise that this study has several limitations. Although data completeness for stage and ethnicity at NCRAS has vastly improved since $2012,{ }^{22}$ a proportion of patients had missing information on disease stage and ethnicity. In addition, we extracted ethnicity information from the same data source to get a similar ethnicity completeness. Yet, ethnicity and stage completeness were slightly higher for the CPES group compared with the cancer registry population, which might be explained by CPES responders being more often admitted to hospital and therefore appearing more in the HES records.

\section{Study implications}

CPES aims to capture patients' experiences across many aspects of their care pathway and has successfully guided cancer policy, the monitoring and improvement of experiences and the development of cancer services across England. ${ }^{11}$ The survey data set is now linked to the cancer registry data, enabling researchers to explore more complex questions such as possible associations between cancer patients' experiences and their clinical outcomes. As we have shown, the representativeness of the data set to the population of cancer patients is limited in some areas and varies between the four cancer types. When using results generated from this data set, cancer policy makers, cancer care providers, patient advocates, charities and health researchers should therefore be aware of several limitations. First, our exploration of this data set found that most of the survey responders were diagnosed close to the survey sampling frame period. This is because the CPES sampling frame is based on a recent hospital treatment, so the patients recruited may not represent the care experience or perspective for all cancer patients. Second, patients responding to the survey were more likely to be diagnosed with earlier stage diseases, and to have a higher median survival. This leads to an underrepresentation of the experiences of patients with poor prognosis, which disproportionally affects certain cancer types. Patients excluded from the survey because of the sampling frame very likely have greater health needs including those for supportive and palliative care which the survey cannot capture. 
Table 3 Odds of breast cancer patients diagnosed between 2001 and 2013 having responded to CPES according to case mix

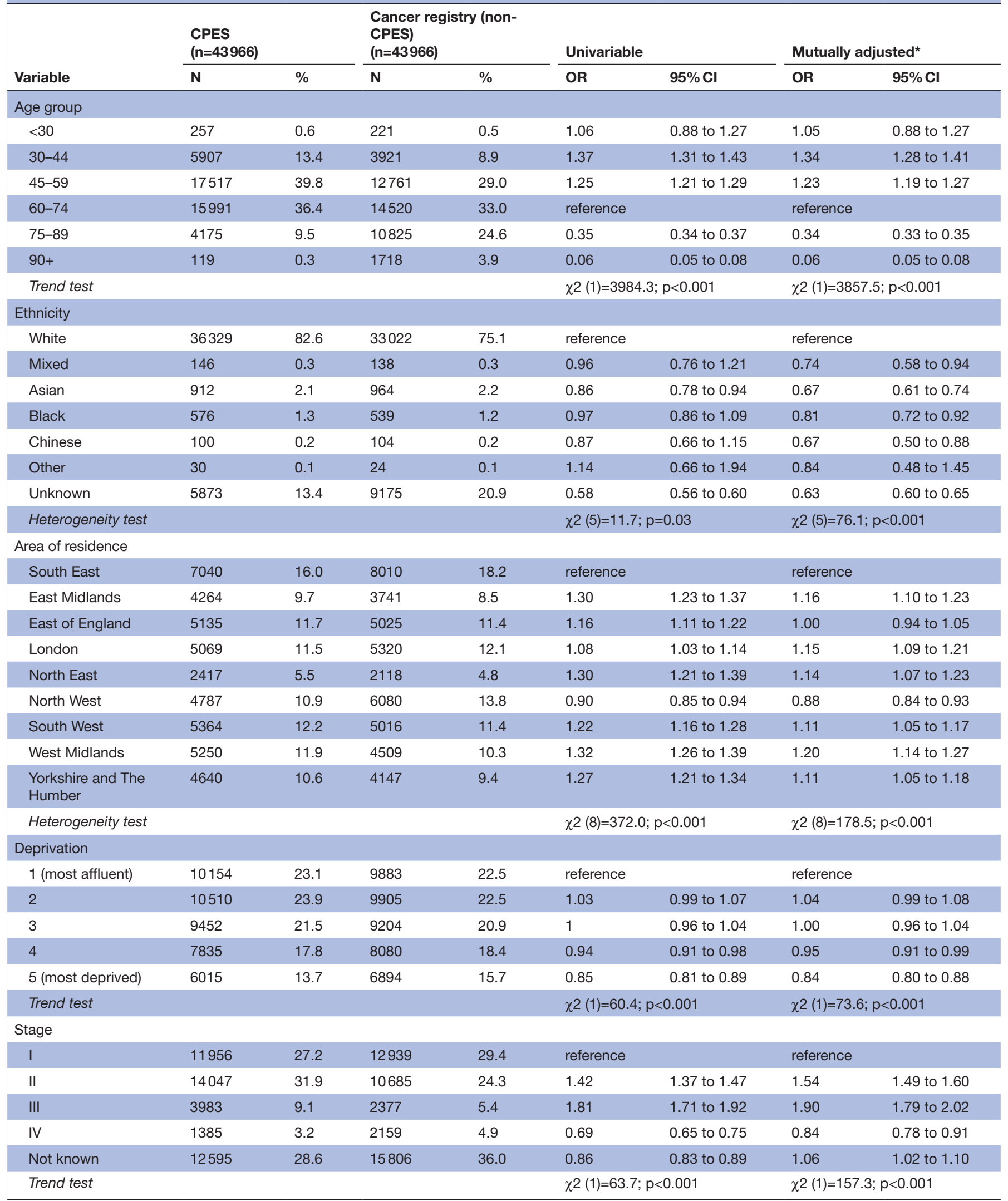

${ }^{* *}$ Multivariable model including all factors; unknown stage and ethnicity categories were not included in tests for heterogeneity and trend.

CPES, National Cancer Patient Experience Survey. 
Table 4 Odds of prostate cancer patients diagnosed between 2001 and 2013 having responded to CPES according to case mix

\begin{tabular}{|c|c|c|c|c|c|c|c|c|}
\hline \multirow[b]{2}{*}{ Variable } & \multicolumn{2}{|c|}{$\begin{array}{l}\text { CPES } \\
(n=20446)\end{array}$} & \multicolumn{2}{|c|}{$\begin{array}{l}\text { Cancer registry (non- } \\
\text { CPES) } \\
\text { (n=20446) }\end{array}$} & \multicolumn{2}{|c|}{ Univariable } & \multicolumn{2}{|c|}{ Mutually adjusted ${ }^{\star}$} \\
\hline & $\mathbf{N}$ & $\%$ & $\mathbf{N}$ & $\%$ & OR & $(95 \% \mathrm{Cl})$ & OR & $95 \% \mathrm{Cl}$ \\
\hline \multicolumn{9}{|l|}{ Age group } \\
\hline$<44$ & 36 & 0.2 & 43 & 0.2 & 0.68 & 0.44 to 1.07 & 0.71 & 0.45 to 1.12 \\
\hline $45-59$ & 2999 & 14.7 & 2106 & 10.3 & 1.11 & 1.04 to 1.18 & 1.15 & 1.08 to 1.23 \\
\hline $60-74$ & 13499 & 66 & 10511 & 51.4 & \multicolumn{2}{|c|}{ reference } & \multicolumn{2}{|c|}{ reference } \\
\hline $75-89$ & 3870 & 18.9 & 7241 & 35.4 & 0.42 & 0.40 to 0.44 & 0.41 & 0.39 to 0.43 \\
\hline $90+$ & 42 & 0.2 & 545 & 2.7 & 0.06 & 0.04 to 0.08 & 0.06 & 0.04 to 0.08 \\
\hline \multicolumn{5}{|l|}{ Trend test } & \multicolumn{2}{|c|}{$\chi^{2}(1)=1501.4 ; p<0.001$} & \multicolumn{2}{|c|}{$\chi 2(1)=1542.7 ; p<0.001$} \\
\hline \multicolumn{9}{|l|}{ Ethnicity } \\
\hline White & 17205 & 84.1 & 15132 & 74.0 & \multicolumn{2}{|c|}{ reference } & \multicolumn{2}{|c|}{ reference } \\
\hline Mixed & 48 & 0.2 & 42 & 0.2 & 1.01 & 0.66 to 1.52 & 0.96 & 0.62 to 1.46 \\
\hline Asian & 204 & 1.1 & 235 & 1.1 & 0.76 & 0.63 to 0.92 & 0.79 & 0.65 to 0.96 \\
\hline Black & 396 & 1.9 & 449 & 2.2 & 0.78 & 0.68 to 0.89 & 0.82 & 0.71 to 0.95 \\
\hline Chinese & 58 & 0.3 & 63 & 0.3 & 0.81 & 0.57 to 1.16 & 0.83 & 0.58 to 1.20 \\
\hline Other & 24 & 0.1 & 8 & 0.1 & 2.64 & 1.19 to 5.87 & 2.29 & 1.02 to 5.16 \\
\hline Unknown & 2511 & 12.3 & 4517 & 22.1 & 0.49 & 0.46 to 0.52 & 0.49 & 0.46 to 0.51 \\
\hline \multicolumn{5}{|c|}{ Heterogeneity test } & \multicolumn{2}{|c|}{$\chi^{2}(5)=27.7 ; p<0.001$} & \multicolumn{2}{|c|}{$\chi^{2}(5)=16.6 ; p=0.005$} \\
\hline \multicolumn{9}{|l|}{$\begin{array}{l}\text { Area of } \\
\text { residence }\end{array}$} \\
\hline South East & 2802 & 13.7 & 3677 & 18.0 & \multicolumn{2}{|c|}{ reference } & \multicolumn{2}{|c|}{ reference } \\
\hline $\begin{array}{l}\text { East } \\
\text { Midlands }\end{array}$ & 2015 & 9.9 & 1712 & 8.4 & 1.54 & 1.42 to 1.67 & 1.47 & 1.35 to 1.60 \\
\hline $\begin{array}{l}\text { East of } \\
\text { England }\end{array}$ & 2378 & 11.6 & 2613 & 12.8 & 1.19 & 1.11 to 1.29 & 1.14 & 1.05 to 1.24 \\
\hline London & 1959 & 9.6 & 2316 & 11.3 & 1.11 & 1.03 to 1.20 & 1.21 & 1.11 to 1.31 \\
\hline North East & 989 & 4.8 & 907 & 4.4 & 1.43 & 1.29 to 1.59 & 1.42 & 1.27 to 1.58 \\
\hline North West & 3737 & 18.3 & 2508 & 12.3 & 1.96 & 1.82 to 2.10 & 2.04 & 1.89 to 2.19 \\
\hline South West & 2721 & 13.3 & 2504 & 12.2 & 1.43 & 1.33 to 1.53 & 1.34 & 1.24 to 1.45 \\
\hline $\begin{array}{l}\text { West } \\
\text { Midlands }\end{array}$ & 2215 & 10.8 & 2217 & 10.8 & 1.31 & 1.21 to 1.42 & 1.26 & 1.16 to 1.36 \\
\hline $\begin{array}{l}\text { Yorkshire } \\
\text { and The } \\
\text { Humber }\end{array}$ & 1630 & 8.0 & 1992 & 9.7 & 1.07 & 0.99 to 1.17 & 1.05 & 0.96 to 1.14 \\
\hline Heterogeneit & $y$ test & & & & $\chi^{2}(8)$ & $p<<0.001$ & $\chi^{2}(8$ & $p<0.001$ \\
\hline \multicolumn{9}{|l|}{ Deprivation } \\
\hline $\begin{array}{l}1 \text { (most } \\
\text { affluent) }\end{array}$ & 5198 & 25.4 & 5019 & 24.5 & \multicolumn{2}{|c|}{ reference } & \multicolumn{2}{|c|}{ Reference } \\
\hline 2 & 5228 & 25.6 & 4886 & 23.9 & 1.03 & 0.98 to 1.09 & 1.01 & 0.95 to 1.07 \\
\hline 3 & 4159 & 20.3 & 4261 & 20.8 & 0.94 & 0.89 to 1.00 & 0.94 & 0.88 to 1.00 \\
\hline 4 & 3278 & 16.0 & 3463 & 16.9 & 0.91 & 0.86 to 0.97 & 0.90 & 0.84 to 0.96 \\
\hline $\begin{array}{l}5 \text { (most } \\
\text { deprived) }\end{array}$ & 2583 & 12.6 & 2817 & 13.8 & 0.89 & 0.83 to 0.95 & 0.83 & 0.78 to 0.90 \\
\hline \multicolumn{3}{|l|}{ Trend test } & & & \multicolumn{2}{|c|}{$\chi^{2}(1)=24.3 ; p<0.001$} & \multirow{2}{*}{\multicolumn{2}{|c|}{$\chi^{2}(1)=40.5 ; p<0.001$}} \\
\hline Stage & & & & & & & & \\
\hline
\end{tabular}


Table 4 Continued

\begin{tabular}{|c|c|c|c|c|c|c|c|c|}
\hline \multirow[b]{2}{*}{ Variable } & \multicolumn{2}{|c|}{$\begin{array}{l}\text { CPES } \\
(n=20446)\end{array}$} & \multicolumn{2}{|c|}{$\begin{array}{l}\text { Cancer registry (non- } \\
\text { CPES) } \\
(n=20446)\end{array}$} & \multicolumn{2}{|c|}{ Univariable } & \multicolumn{2}{|c|}{ Mutually adjusted* } \\
\hline & $\mathbf{N}$ & $\%$ & $\mathbf{N}$ & $\%$ & OR & $(95 \% \mathrm{Cl})$ & OR & $95 \% \mathrm{Cl}$ \\
\hline 1 & 3081 & 15.1 & 3044 & 14.9 & \multicolumn{2}{|l|}{ reference } & \multicolumn{2}{|c|}{ Reference } \\
\hline II & 3032 & 14.8 & 2560 & 12.5 & 1.37 & 1.27 to 1.47 & 1.20 & 1.12 to 1.30 \\
\hline Not known & 9951 & 48.7 & 10895 & 53.3 & 0.95 & 0.89 to 1.02 & 1.08 & 1.01 to 1.14 \\
\hline Trend test & & & & & \multicolumn{2}{|c|}{$\chi 2(1)=0.0 ; p=0.7$} & \multicolumn{2}{|c|}{$\chi^{2}(1)=12.9 ; p<0.001$} \\
\hline
\end{tabular}

*Multivariable model including all factors; unknown stage and ethnicity categories were not included in tests for heterogeneity and trend. CPES, National Cancer Patient Experience Survey.

In addition, there are notable differences in responders by cancer type by comparison with the cancer incidence registered every year in England. For example, out of all lung cancer incident cases diagnosed between 2011 and 2013 (incidents $\mathrm{n}=107431$ ), only $9 \%$ were captured in CPES $(n=9381)$ compared with 22\% $(n=28781)$ for breast cancer (incidents $\mathrm{n}=128552) .{ }^{27}$ As a consequence, the number of responses for individual cancer types may be too low to be reported and considered at a local level or to show improvement. This is particularly problematic for lung cancer-the most common cancer in males and females combined and the biggest killer of all the cancers. ${ }^{28}$ Work is therefore needed to recruit more patients with poor prognosis cancers in particular, so that cancer services can be designed based on these patients' experiences and comments rather than on data from a mix of patients with other cancers. This might involve additional surveys that seek to capture experiences in the early part of the referral, investigation and diagnosis pathway from a larger number of patients. An alternative is to expand the current sampling frame or move to continuous sampling throughout the year for patients with poor prognosis cancers. For example, the Consumer Assessment of Healthcare Providers and Systems has made efforts and initiatives to capture unrepresented patients' voices. ${ }^{29}$ Another example of a study including unrepresented patients is one carried in Denmark which aimed to capture lung cancer patient-reported outcomes at a nationwide level. ${ }^{21}$ Future efforts should assess the feasibility of adopting similar methods for CPES as well as on the reasons behind the low response rates among patients with advanced stage disease, older patients and those from non-White ethnic backgrounds.

\section{CONCLUSION}

This study demonstrates that while CPES has been a valuable tool for the large-scale reporting of patient experience, it does not necessarily represent all cancer patients in terms of patient and tumour stage at diagnosis for the four main cancers. These limitations need to be acknowledged by cancer policy makers, charities, cancer services and patient representatives using the findings and by researchers interpreting results from the survey and the linked registry data set. Future research should examine the feasibility of applying either supplementary focused or more continuous surveys for the underrepresented groups of patients to capture their missing care experiences.

\section{Author affiliations}

${ }^{1}$ Cancer Epidemiology, Population and Global Health, Comprehensive Cancer Centre, Faculty of Life Sciences \& Medicine, King's College London, London, UK

${ }^{2}$ College of Health Science, Public Health Section, Saudi Electronic University, Riyadh, Saudi Arabia

${ }^{3}$ Consumer Forum, NCRI CSG (Lung) Subgroup, BTOG Steering Committee, NHSE CEG, National Cancer Research Institute, London, UK

${ }^{4}$ Consumer Involvement Advisory Group, Consumer Forum, National Cancer Research Institute, London, UK

${ }^{5}$ National Cancer Registration and Analysis Service, Public Health England, London, UK

\section{Twitter Saleh A Alessy @SalehAleesy}

Acknowledgements Data for this study is based on patient-level information collected by the NHS. The data are collated, maintained and quality assured by Public Health England, National Cancer Registration and Analysis Service. We also would like to thank Dr Joanna Pethick from Public Health England, National Cancer Registration and Analysis Service, for her suggestions on extracting the linked data set.

Contributors All authors (SAA, EAD, JR, MB and ML) contributed to the conception of the study. SAA, ML and EAD designed the study and decided the analytic approaches. SAA and ML were responsible for extracting and analysing the data. All authors contributed to the interpretation of the results and the writing of this manuscript.

Funding The authors have not declared a specific grant for this research from any funding agency in the public, commercial or not-for-profit sectors.

Competing interests None declared.

Patient consent for publication Not required.

Ethics approval The National Cancer Registration and Analysis Service received approval from the Confidentiality Advisory Group of the National Health Service (NHS) Health Research Authority to carry out surveillance using the data they collect on all cancer patients under section 251 of the NHS Act 2006. SAA (the lead author) is a PhD student at King's College London and has been guaranteed a studentship agreement with the National Cancer Registration and Analysis Service at Public Health England. Therefore, separate ethical approval was not required for this study. Provenance and peer review Not commissioned; externally peer reviewed. 
Data availability statement Data may be obtained from a third party and are not publicly available.

Open access This is an open access article distributed in accordance with the Creative Commons Attribution Non Commercial (CC BY-NC 4.0) license, which permits others to distribute, remix, adapt, build upon this work non-commercially, and license their derivative works on different terms, provided the original work is properly cited, appropriate credit is given, any changes made indicated, and the use is non-commercial. See: http://creativecommons.org/licenses/by-nc/4.0/.

\section{ORCID iD}

Saleh A Alessy http://orcid.org/0000-0003-4588-7410

\section{REFERENCES}

1 Coulter A, Fitzpatrick R, Cornwell J. Measures of patients ' experience in hospital: purpose methods and uses 2009.

2 Browne K, Roseman D, Shaller D, et al. analysis \& commentary Measuring Patient Experience As A Strategy For Improving Primary Care. Health Aff 2010;29:921-5.

3 Anhang Price R, Elliott MN, Zaslavsky AM, et al. Examining the role of patient experience surveys in measuring health care quality. Med Care Res Rev 2014;71:522-54.

4 Davies E, Shaller D, Edgman-Levitan S, et al. Evaluating the use of a modified CAHPS $®$ survey to support improvements in patientcentred care: lessons from a quality improvement collaborative. Health Expect 2008;11:160-76.

5 The Health Quality Council of Alberta. Primary care patient experience survey, 2019. Available: https://hqca.ca/surveys/patientexperience-survey/ [Accessed 14 Jan 2019].

6 The CAHPS Program. CAHPS cancer care survey, 2019. Available: https://www.ahrq.gov/cahps/about-cahps/cahps-program/index.html [Accessed 14 Jan 2019].

7 Australian Institute of Health and Welfare. Patient experiences in Australia in 2016-17, 2019. Available: https://www.aihw.gov.au/ reports/primary-health-care/patient-experiences-in-australia-in2016-17/contents/summary [Accessed 14 Jan 2019].

8 Cleary PD. Evolving concepts of patient-centered care and the assessment of patient care experiences: optimism and opposition. $J$ Health Polit Policy Law 2016;41:675-96.

9 Alessy SA, Lüchtenborg M, Davies EA. How have patients' experiences of cancer care been linked to survival? A systematic review. Patient Exp J 2019;6:63-80.

10 Madden PB, Davies EA. Reporting cancer patients' experiences of care for quality improvement: analysis of 2000 and 2004 survey results for South East England. J Eval Clin Pract 2010;16:776-83.

11 The Independent Cancer Taskforce. Achieving World-Class cancer outcomes, 2015. Available: https://www.cancerresearchuk.org/sites/ default/files/achieving_world-class_cancer_outcomes_-_a_strategy_ for_england_2015-2020.pdf

12 Department of Health. National cancer patient experience. survey programme. 2010 national survey report 2010:1-142.

13 El Turabi A, Abel GA, Roland M, et al. Variation in reported experience of involvement in cancer treatment decision making: evidence from the National cancer patient experience survey. $\mathrm{Br} \mathrm{J}$ Cancer 2013;109:780-7.

14 Bone A, Mc Grath-Lone L, Day S, et al. Inequalities in the care experiences of patients with cancer: analysis of data from the National cancer patient experience survey 2011-2012. BMJ Open 2014;4:e004567.

15 Saunders CL, Abel GA, Lyratzopoulos G. Inequalities in reported cancer patient experience by socio-demographic characteristic and cancer site: evidence from respondents to the English cancer patient experience survey. Eur J Cancer Care 2015;24:85-98.

16 Pinder RJ, Ferguson J, Møller H. Minority ethnicity patient satisfaction and experience: results of the National cancer patient experience survey in England. BMJ Open 2016;6:e011938.

17 Saunders CL, Abel GA, Lyratzopoulos G. What explains worse patient experience in London? Evidence from secondary analysis of the cancer patient experience survey. BMJ Open 2014;4:e004039.

$18 \mathrm{Z}-\mathrm{H} \mathrm{H}$, Connett JE, Yuan J-M, et al. Role of survivor bias in pancreatic cancer case-control studies. Ann Epidemiol 2016;26:50-6.

19 Etter J-F, Perneger TV. Analysis of non-response bias in a mailed health survey. J Clin Epidemiol 1997;50:1123-8.

20 Abel GA, Saunders CL, Lyratzopoulos G. Post-sampling mortality and non-response patterns in the English cancer patient experience survey: implications for epidemiological studies based on surveys of cancer patients. Cancer Epidemiol 2016;41:34-41.

21 Brønserud MM, lachina M, Green A, et al. Patient-Reported outcomes (pros) in lung cancer: experiences from a nationwide feasibility study. Lung Cancer 2019;128:67-73.

22 Henson KE, Elliss-Brookes L, Coupland VH, et al. Data resource profile: National cancer registration dataset in England. Int $J$ Epidemiol;45.

23 Carneiro IG, Charnock J, Fry A, et al. Linking the English cancer patient experience survey to cancer registration: relating patient experience to outcomes, a step towards better services and outcomes. Int J Popul Data Sci 2017;1.

24 NHS Digital. Hospital episode statistics, 2018. Available: https:// digital.nhs.uk/data-and-information/data-tools-and-services/dataservices/hospital-episode-statistics\#summary [Accessed 7 Jul 2019].

25 National Statistics. English indices of deprivation 2015, 2015. Available: https://www.gov.uk/government/statistics/english-indicesof-deprivation-2015 [Accessed 14 Nov 2018].

26 Health and Social Care Information Centre. National lung cancer audit report 2014, 2014. Available: https://www.hqip.org.uk/wpcontent/uploads/2018/02/4r4onf.pdf [Accessed 12 Nov 2018].

27 Office for National Statistics. Cancer registration statistics, England statistical bulletins: 2017, 2019. Available: https://www.ons.gov. uk/peoplepopulationandcommunity/healthandsocialcare/cond itionsanddiseases/bulletins/cancerregistrationstatisticsengland/ previousReleases [Accessed 24 Mar 2019].

28 Office for National Statistics. Cancer survival in England, 2019. Available: https://www.ons.gov.uk/peoplepopulationandcommunity/ healthandsocialcare/conditionsanddiseases/bulletins/cancersu rvivalinengland/nationalestimatesforpatientsfollowedupto2017 [Accessed 11 Mar 2019].

29 Anhang Price R, Elliott MN. Measuring Patient-Centeredness of care for seriously ill individuals: challenges and opportunities for accountability initiatives. J Palliat Med 2018;21:S-28-S-35. 